Pacific Journal of Mathematics

REGULAR OPERATOR APPROXIMATION THEORY

HAL ANSELONE AND MIKE TREUDEN 


\title{
REGULAR OPERATOR APPROXIMATION THEORY
}

\author{
P. M. ANSELONE AND M. L. TREUden
}

Regular operator approximation theory applies to finite difference approximations for differential equations and numerical integration approximations for integral equations. New relationships and efficient derivations of known results are presented. The analysis is based on the systematic use of convergence and compactness properties of sequences of sets. Since the purpose is theoretical, applications are merely indicated and references are cited.

1. Introduction and Summary. Regular operator approximation theory applies to numerical solutions of differential and integral equations. Some pertinent references are Anselone and Ansorge [3, 4], Chatelin [6], Grigorieff [7, 8], Stummel [10], and Vainikko [12].

We focus here on linear equations in a Banach space setting. Approximations are defined in the same setting. This case serves to motivate ideas and results for the more complicated situation with approximations defined in different spaces related by connection maps, such as restriction and interpolation. We present particularly efficient and revealing derivations of basic convergence results and we extend the theory in several significant respects. The analysis is based on systematic use of convergence and compactness concepts for sequences of sets. Some of these ideas were exploited in nonlinear operator approximation theory in [3]. These concepts should be useful also in general approximation theory.

Let $X$ and $Y$ be Banach spaces. A sequence of elements in $X$ or $Y$ is discretely compact (d-compact for short) if every subsequence has a convergent subsequence.

Let $A, A_{n} \in L(X, Y)$ the space of bounded linear operators from $X$ to $Y$. We shall compare equations

$$
A x=y, \quad A_{n} x_{n}=y,
$$

where $A_{n} \rightarrow A$ pointwise and $\left\{A_{n}\right\}$ is asymptotically regular, i.e., if $\left\{x_{n}\right\}$ is bounded and $\left\{A_{n} x_{n}\right\}$ is d-compact, then $\left\{x_{n}\right\}$ is d-compact. Results concern inverse operators, null spaces, and ranges. There are implications for eigenvalues and eigenvectors.

Sharper results can be given for equations

$$
(I-K) x=y, \quad\left(I-K_{n}\right) x_{n}=y,
$$


where $K, K_{n} \in L(X)$ with $K_{n} \rightarrow K$ and either $\left\{K_{n}\right\}$ is collectively compact, i.e., $\widehat{\cup K_{n} S}$ is compact for any bounded set $S \subset X$, or $\left\{K_{n}\right\}$ is asymptotically compact, i.e., $\left\{K_{n} x_{n}\right\}$ is d-compact for any bounded sequence $\left\{x_{n}\right\}$ in $X$. Results for the collectively compact case presented in [1] will be extended to the more general asymptotically compact case in a forthcoming sequel.

For expository continuity, the paper is largely self-contained.

2. Convergence and compactness concepts. This material is valid also in a metric space. For convenience, we stay in a Banach space $X$. Notation:

$$
x, x_{n} \in X, \quad S, S_{n} \subset X, \quad n \in N=\{1,2, \ldots\} .
$$

We introduce $\varepsilon$-neighborhoods of sets,

$$
\Omega_{\varepsilon}(S)=\bigcup_{x \in S}\{y \in X:\|x-y\|<\varepsilon\}, \quad \varepsilon>0 .
$$

By analogy with point convergence, $x_{n} \rightarrow x$ as $n \rightarrow \infty$, set convergence is defined by

$$
S_{n} \rightarrow S \text { if } S_{n} \subset \Omega_{\varepsilon}(S) \forall n \text { large } \forall \varepsilon>0,
$$

i.e., for $n \geq n_{\varepsilon}$ with some $n_{\varepsilon}$. Such set limits are not unique:

$$
S_{n} \rightarrow S \subset S^{\prime} \Rightarrow S_{n} \rightarrow S^{\prime} .
$$

The void set $\varnothing$ plays a special role: $\Omega_{\varepsilon}(\varnothing)=\varnothing$ and

$$
\begin{gathered}
S_{n} \rightarrow \varnothing \Rightarrow S_{n}=\varnothing \quad \forall n \text { large, } \\
S_{n}=\varnothing \forall n \text { large } \Rightarrow S_{n} \rightarrow S \forall S \subset X .
\end{gathered}
$$

For $S$ compact,

$$
S_{n} \rightarrow S \Leftrightarrow \forall \text { open } \Omega \supset S, \Omega \supset S_{n} \forall n \text { large, }
$$

i.e., for $n \geq n_{\Omega}$ with some $n_{\Omega}$.

Denote infinite subsequences of $N$ by $N^{\prime}, N^{\prime \prime}$, etc. Sets of cluster points (limits of subsequences) of $\left\{x_{n}\right\}$ and $\left\{S_{n}\right\}$ are:

$$
\begin{aligned}
& \left\{x_{n}\right\}^{*}=\left\{x \in X: x_{n} \rightarrow x, n \in N^{\prime}\right\}, \\
& \left\{S_{n}\right\}^{*}=\left\{x \in X: x_{n} \rightarrow x, x_{n} \in S_{n}, n \in N^{\prime}\right\} .
\end{aligned}
$$

All such cluster point sets are closed. A sequence $\left\{x_{n}\right\}$ is discretely compact (d-compact) if every subsequence has a convergent subsequence, hence a cluster point. Similarly, $\left\{S_{n}\right\}$ is d-compact if every sequence $\left\{x_{n}\right.$ : $\left.n \in N^{\prime}\right\}$ with $x_{n} \in S_{n}$ has a convergent subsequence. 
Elementary properties include

(2.5) $\left\{S_{n}\right\}$ d-compact, $\left\{S_{n}\right\}^{*}=\varnothing \Rightarrow S_{n}=\varnothing \forall n$ large,

(2.6) $\left\{\bar{S}_{n}\right\}^{*}=\left\{S_{n}\right\}^{*}$,

(2.7) $\left\{\bar{S}_{n}\right\}$ d-compact $\Leftrightarrow\left\{S_{n}\right\}$ d-compact,

(2.8) $\bar{S}_{n} \rightarrow S \Leftrightarrow S_{n} \rightarrow S$,

(2.9) $\overline{\cup S_{n}}=\left(\cup \bar{S}_{n}\right) \cup\left\{S_{n}\right\}^{*}$,

(2.10) $\overline{\cup S_{n}}$ compact $\Leftrightarrow \bar{S}_{n}$ compact $\forall n,\left\{S_{n}\right\}$ d-compact.

THEOREM 2.1 .

(a) $\left\{S_{n}\right\}$ d-compact $\Leftrightarrow\left\{S_{n}\right\}^{*}$ compact, $S_{n} \rightarrow\left\{S_{n}\right\}^{*}$.

(b) $\left\{S_{n}\right\}$ d-compact, $\left\{S_{n}\right\}^{*} \subset S \Rightarrow S_{n} \rightarrow S$.

Proof. (a) $\Rightarrow$ (b). Prove (a).

1. Assume $\left\{S_{n}\right\}$ d-compact. Let $x_{i} \in\left\{S_{n}\right\}^{*}$ for $i \in N$. Then $\exists n_{i}<$ $n_{i+1}$ and $x_{n_{i}} \in S_{n_{i}}$ such that $\left\|x_{n_{i}}-x_{i}\right\| \rightarrow 0$. Since $\left\{S_{n}\right\}$ is d-compact, $\exists N^{\prime}$ and $x \in X$ such that $x_{n_{i}} \rightarrow x$ with $i \in N^{\prime}$. Hence, $x_{i} \rightarrow x$ with $i \in N^{\prime}$ and $\left\{S_{n}\right\}^{*}$ is compact.

2. Assume $S_{n} \rightarrow\left\{S_{n}\right\}^{*}$ fails. Then $\exists \varepsilon>0, N^{\prime}$ and $x_{n} \in S_{n}$ for $n \in N^{\prime}$ such that $\left\|x_{n}-x\right\|>\varepsilon$ for all $n \in N^{\prime}$ and $x \in\left\{S_{n}\right\}^{*}$. Hence, $\left\{x_{n}\right.$ : $\left.n \in N^{\prime}\right\}^{*}=\varnothing$ and $\left\{S_{n}\right\}$ is not d-compact. Thus, $\left\{S_{n}\right\}$ d-compact $\Rightarrow S_{n}$ $\rightarrow\left\{S_{n}\right\}^{*}$.

3. Assume $\left\{S_{n}\right\}^{*}$ compact and $S_{n} \rightarrow\left\{S_{n}\right\}^{*}$. Let $x_{n} \in S_{n}$ for $n \in N^{\prime}$. Since $S_{n} \rightarrow\left\{S_{n}\right\}^{*}, \exists N^{\prime \prime} \subset N^{\prime}$ and $x^{n} \in\left\{S_{n}\right\}^{*}$ for $n \in N^{\prime \prime}$ such that $\left\|x^{n}-x_{n}\right\| \rightarrow 0$ with $n \in N^{\prime \prime}$. Since $\left\{S_{n}\right\}^{*}$ is compact, $\exists N^{\prime \prime \prime} \subset N^{\prime \prime}$ and $x \in X$ such that $x^{n} \rightarrow x$ with $n \in N^{\prime \prime \prime}$. Then $x_{n} \rightarrow x$ with $n \in N^{\prime \prime \prime}$ and $\left\{S_{n}\right\}$ is d-compact.

For other relations involving convergence and d-compactness of sequences of sets, see [3].

Next we introduce analogues of "cover compactness" and total boundedness for sequences of sets. Let $\left\{S_{n}\right\}$ be asymptotically compact if for any open cover of $\overline{\cup S_{n}} \exists n_{0}$ and a finite subcover of $\overline{U_{n \geq n_{0}} S_{n}}$. Let $\left\{S_{n}\right\}$ be asymptotically totally bounded if $\forall \varepsilon>0 \exists n_{\varepsilon}$ such that $\bigcup_{n \geq n_{\varepsilon}} S_{n}$ has a finite $\varepsilon$-net. The following theorem generalizes the equivalence of relative compactness, sequential compactness and total boundedness for sets in a complete metric space.

THEOREM 2.2.

(a) $\left\{S_{n}\right\}$ d-compact $\Leftrightarrow\left\{S_{n}\right\}$ asymptotically compact.

(b) $\left\{S_{n}\right\}$ d-compact $\Leftrightarrow\left\{S_{n}\right\}$ asymptotically totally bounded. 


\section{Proof.}

1. Assume $\left\{S_{n}\right\}$ d-compact. Let $\overline{\cup S_{n}} \subset \cup_{\alpha \in A} O_{\alpha}, O_{\alpha}$ open. By (2.9) and Theorem 2.1, $\left\{S_{n}\right\}^{*} \subset \cup_{\alpha \in A} O_{\alpha}$ and $\left\{S_{n}\right\}^{*}$ is compact. So $\left\{S_{n}\right\}^{*} \subset$ $\cup_{\alpha \in B} O_{\alpha}$ for some finite $B \subset A$. By (2.8) and Theorem 2.1, $\bar{S}_{n} \rightarrow\left\{S_{n}\right\}^{*}$. By (2.4) and (2.9), $\overline{\cup_{n \geq n_{0}} S_{n}} \subset \cup_{\alpha \in B} O_{\alpha}$ for some $n_{0}$. Thus, $\left\{S_{n}\right\}$ is asymptotically compact.

2. Assume $\left\{S_{n}\right\}$ is not d-compact. Then $\exists x_{n} \in S_{n}, n \in N^{\prime}$, such that $\left\{x_{n}\right\}^{*}=\varnothing$ and, moreover, $x_{m} \neq x_{n}$ for $m \neq n$. Then $\bigcup\left\{x_{n}\right\}$ is closed and $\Omega=\left[\bigcup\left\{x_{n}\right\}\right]^{\mathrm{c}}$ is open. For each $n \in N^{\prime} \exists \Omega_{n}$ open with $x_{n} \in \Omega_{n}$ and $x_{m} \notin \Omega_{n}$ for $m \neq n$. Now $\overline{\cup S_{n}} \subset\left(\cup \Omega_{n}\right) \cup \Omega=X$. There is no finite subcover of $\overline{U_{n \geq n_{0}} S_{n}}$ for any $n_{0}$. So $\left\{S_{n}\right\}$ is not asymptotically compact. This proves part (a) of the theorem.

3. Assume $\left\{S_{n}\right\}$ d-compact. By Theorem 2.1, $\left\{S_{n}\right\}^{*}$ is compact, hence totally bounded: $\forall \varepsilon>0 \exists$ a finite set $C_{\varepsilon} \subset X$ such that $\left\{S_{n}\right\}^{*} \subset \Omega_{\varepsilon}\left(C_{\varepsilon}\right)$. By Theorem 2.1, $S_{n} \rightarrow\left\{S_{n}\right\}^{*}$ and $S_{n} \subset \Omega_{\varepsilon}\left(\left\{S_{n}\right\}^{*}\right) \subset \Omega_{2 \varepsilon}\left(C_{\varepsilon}\right)$ for $n$ large. So $\left\{S_{n}\right\}$ is asymptotically totally bounded.

4. Assume $\left\{S_{n}\right\}$ asymptotically totally bounded. For each $m=$ $1,2, \ldots, \exists$ a finite set $C_{m} \subset X$ and $n_{m} \in N$ such that $\bigcup_{n \geq n_{m}} S_{n} \subset \Omega_{2^{-m}}\left(C_{m}\right)$. Let $x_{n} \in S_{n}$ for $n \in N^{\prime}$. Then

$\exists N_{1} \subset N^{\prime}$ and $y_{1} \in C_{1}$ such that $x_{n} \in \Omega_{2^{-1}}\left(y_{1}\right) \quad \forall n \in N_{1}$,

$\exists N_{2} \subset N_{1}$ and $y_{2} \in C_{2}$ such that $x_{n} \in \Omega_{2^{-2}}\left(y_{2}\right) \quad \forall n \in N_{2}$,

and so on. Choose $n_{1} \in N_{1}$ and $n_{1}<n_{2} \in N_{2}$, etc. Then $x_{n_{l}} \in \Omega_{2^{-l}}\left(y_{l}\right)$ with $y_{l} \in C_{i}$. Hence, $\left\|x_{n_{l}}-x_{n_{l}}\right\|<1 / 2^{i-1}$ for $i<j$, so $\left\{x_{n_{t}}\right\}$ is Cauchy. Since $X$ is complete, $x_{n_{l}} \rightarrow x$ for some $x \in X$. Therefore, $\left\{S_{n}\right\}$ is d-compact. This proves part (b) of the theorem.

3. Dimension and codimension. Let $E, E_{n}$ and $F$ be closed subspaces of $X$. Let

$$
U=\{x \in X:\|x\|=1\},
$$

the unit sphere in $X$. Recall that

$$
\operatorname{dim} F<\infty \Leftrightarrow F \cap U \text { compact. }
$$

Lemma 3.1. Assume $\left\{E_{n}\right\}^{*} \subset E$ and either $\left\{E_{n} \cap U\right\}$ is d-compact or $\operatorname{dim} F<\infty$. Then

$$
E \cap F=\{0\} \Rightarrow E_{n} \cap F=\{0\} \quad \forall \text { large. }
$$

Proof. In either case, $\left\{E_{n} \cap F \cap U\right\}$ is d-compact and

$$
\left\{E_{n} \cap F \cap U\right\}^{*} \subset E \cap F \cap U=\varnothing .
$$


By (2.5),

$$
E_{n} \cap F \cap U=\varnothing \quad \forall n \text { large. }
$$

Hence,

$$
E_{n} \cap F=\{0\} \quad \forall n \text { large. }
$$

THEOREM 3.2. Assume $\left\{E_{n} \cap U\right\}$ d-compact, $\left\{E_{n}\right\}^{*} \subset E$, and $\operatorname{dim} E$ $<\infty$. Then $\operatorname{dim} E_{n} \leq \operatorname{dim} E \forall n$ large.

Proof. Since $\operatorname{dim} E<\infty$, there is a closed subspace $F$ such that $X=E \oplus F$. Thus, $E \cap F=\{0\}$. By Lemma 3.1, $E_{n} \cap F=\{0\} \forall n$ large. Hence, $\operatorname{dim} E_{n} \leq \operatorname{codim} F=\operatorname{dim} E \forall n$ large.

THEOREM 3.3. Let $\left\{E_{n}\right\}^{*} \subset E$.

(a) $\operatorname{codim} E<\infty \Rightarrow \operatorname{codim} E_{n} \geq \operatorname{codim} E \quad \forall n$ large.

(b) $\operatorname{codim} E=\infty \Rightarrow \operatorname{codim} E_{n} \rightarrow \infty$ as $n \rightarrow \infty$.

Proof. Let $\operatorname{dim} F<\infty$ and $E \cap F=\{0\}$. By Lemma 3.1, $E_{n} \cap F=$ $\{0\} \forall n$ large. Therefore,

$$
\operatorname{codim} E \geq m \Rightarrow \operatorname{codim} E_{n} \geq m \quad \forall n \text { large. }
$$

This implies both (a) and (b).

4. Operator fundamentals. We record for later use some basic facts about bounded linear operators. Let $N(A)$ and $R(A)$ denote the null space and range of $A \in L(X, Y)$. Recall $\|A\|=\sup \{\|A x\|: x \in U\}$.

(4.1) $\exists A^{-1} \Leftrightarrow N(A)=\{0\} \Leftrightarrow 0 \notin A U$.

(4.2) $\exists A^{-1}$ bounded $\Leftrightarrow 0 \notin \overline{A U}$.

(4.3) $A U$ closed, $\exists A^{-1} \Rightarrow A^{-1}$ bounded.

(4.4) Let $\exists A^{-1}$. Then $A^{-1}$ bounded $\Leftrightarrow R(A)$ closed.

LeMma 4.1. Assume $\operatorname{dim} N(A)<\infty$. Then there is a closed subspace $F \subset X$ such that $X=N(A) \oplus F$. Let $A_{F}=\left.A\right|_{F}$. Then $\exists A_{F}^{-1}, R\left(A_{F}\right)=$ $R(A)$, and

$$
R(A) \text { is closed } \Leftrightarrow A_{F}^{-1} \text { is bounded } .
$$

Let $P$ and $Q$ be the complementary projections in $L(X)$ with ranges $R(P)=N(A)$ and $R(Q)=F$. Then $P+Q=I, A P=0$, and $A=A Q=$ $A_{F} Q$.

The index of $A$ is given by

$$
\operatorname{ind}(A)=\operatorname{dim} N(A)-\operatorname{codim} R(A)
$$


when the right member is well defined. Thus, $-\infty \leq \operatorname{ind}(A) \leq+\infty$.

Lemma $4.2[9,11]$. Let $A=A_{1}+A_{2}$ with $R\left(A_{1}\right)$ closed, $\exists \operatorname{ind}\left(A_{1}\right)$, and $\operatorname{dim} R\left(A_{2}\right)<\infty$. Then $R(A)$ is closed and $\operatorname{ind}(A)=\operatorname{ind}\left(A_{1}\right)$.

5. Compact operators. Two equivalent definitions of a compact operator $K \in L(X)$ are given.

\section{K compact:}

$S$ bounded $\Rightarrow \overline{K S}$ compact,

$\left\{x_{n}\right\}$ bounded $\Rightarrow\left\{K x_{n}\right\}$ d-compact.

For example, if $\operatorname{dim} R(K)<\infty$ then $K$ is compact. Some well-known properties of compact operators are

(5.1) $\operatorname{dim} N(I-K)<\infty, R(I-K)$ closed, and the extended Fredholm alternative:

(5.2) $R(I-K)=X \Leftrightarrow \exists(I-K)^{-1} \Rightarrow(I-K)^{-1} \in L(X)$,

(5.3) ind $(I-K)=0$.

6. Regular operators. Three equivalent definitions of a regular operator $A \in L(X, Y)$ are given.

A regular:

$S$ bounded, $\overline{A S}$ compact $\Rightarrow \bar{S}$ compact, $\left\{x_{n}\right\}$ bounded, $\left\{A x_{n}\right\}$ d-compact $\Rightarrow\left\{x_{n}\right\}$ d-compact, $\left\{x_{n}\right\}$ bounded, $A x_{n} \rightarrow y \Rightarrow\left\{x_{n}\right\}^{*} \neq \varnothing$.

Examples of regular operators are

(6.1) $\exists A^{-1}$ bounded $\Rightarrow A$ regular,

(6.2) $K \in L(X), K$ compact $\Rightarrow I-K$ regular.

From the definition of a regular operator, restrictions and products of regular operators are regular, and

(6.3) $A$ regular, $\left\{x_{n}\right\}$ bounded, $A x_{n} \rightarrow y \Rightarrow A x=y \forall x \in\left\{x_{n}\right\}^{*}$,

(6.4) $A$ regular, $S$ closed bounded $\Rightarrow A S$ closed.

Thus, $A$ regular $\Rightarrow A U$ closed. By (4.3), (4.4), and (6.1),

(6.5) whenever $\exists A^{-1}$,

$A$ regular $\Leftrightarrow A^{-1}$ bounded $\Leftrightarrow R(A)$ closed.

THEOREM 6.1 (Wolf [13]).

A regular $\Leftrightarrow \operatorname{dim} N(A)<\infty, R(A)$ closed. 
Proof. Let $S=U \cap N(A)$ in the definition of $A$ regular. By (3.2), $A$ regular $\Rightarrow \operatorname{dim} N(A)<\infty$. Now assume $\operatorname{dim} N(A)<\infty$. Refer to Lemma 4.1. Since $\operatorname{dim} R(P)<\infty, P$ is compact. By (6.2), $Q=I-P$ is regular. Since $A=A_{F} Q$, and restrictions and products of regular operators are regular, $A$ regular $\Leftrightarrow A_{F}$ regular. By $(6.5), A_{F}$ regular $\Leftrightarrow R\left(A_{F}\right)$ closed. Since $R\left(A_{F}\right)=R(A)$,

$A$ regular $\Leftrightarrow A_{F}$ regular $\Leftrightarrow R\left(A_{F}\right)$ closed $\Leftrightarrow R(A)$ closed, when $\operatorname{dim} N(A)<\infty$. The theorem follows.

In other terminology, $A$ is regular iff $A$ is a semi-Fredholm operator with $-\infty \leq \operatorname{ind}(A)<\infty$.

REMARK. Regular operators are related to the notion of a proper mapping. Recall that a continuous map $f$ between topological spaces is proper if $f^{-1}(S)$ is compact whenever $S$ is compact. It is not difficult to show that a linear operator $A$ is regular iff the restriction of $A$ to each closed, bounded set is proper. It is from this viewpoint that the previous theorem can also be attributed to Yood [14].

7. Stable convergence. We shall need a few basic facts about operator convergence. Let $A, A_{n} \in L(X, Y)$. Denote pointwise convergence on $X$ by $A_{n} \rightarrow A$. If $A_{n} \rightarrow A$ then $\left\{A_{n}\right\}$ is bounded uniformly and there is continuous convergence: $x_{n} \rightarrow x \Rightarrow A_{n} x_{n} \rightarrow A x$. Moreover,

$$
A_{n} \rightarrow A \Rightarrow\left\{N\left(A_{n}\right)\right\}^{*} \subset N(A), \quad\left\{R\left(A_{n}\right)\right\}^{*} \supset R(A) .
$$

The special cases with $N(A)=\{0\}$ and $R(A)=Y$ are worth noting.

Define

$\left\{A_{n}\right\}$ stable:

$\exists A_{n}^{-1}$ bounded uniformly $\forall n$ large,

stable convergence $A_{n} \stackrel{\mathrm{s}}{\rightarrow} A$ :

$A_{n} \rightarrow A,\left\{A_{n}\right\}$ stable, $R\left(A_{n}\right)=Y \forall n$ large.

From (4.4)

$$
\left\{A_{n}\right\} \text { stable } \Rightarrow R\left(A_{n}\right) \text { closed } \forall n \text { large. }
$$

By analogy with (4.2),

$$
\left\{A_{n}\right\} \text { stable } \Leftrightarrow 0 \notin\left\{A_{n} U\right\}^{*} .
$$

Since $A_{n} \rightarrow A$ implies $\overline{A U} \subset\left\{A_{n} U\right\}^{*}$,

$$
A_{n} \stackrel{\mathrm{s}}{\rightarrow} A \Rightarrow \exists A^{-1} \text { bounded, } R(A) \text { closed. }
$$


Since $A_{n}^{-1}-A^{-1}=A_{n}^{-1}\left(A-A_{n}\right) A^{-1}$ when $A^{-1}, A_{n}^{-1} \in L(Y, X)$,

$$
\begin{aligned}
A_{n} & \stackrel{\mathrm{s}}{\rightarrow} A, R(A)=Y, A x=y, A_{n} x_{n}=y \\
& \Rightarrow A_{n}^{-1} \rightarrow A^{-1},\left\|x_{n}-x\right\| \leq\left\|A_{n}^{-1}\right\|\left\|A_{n} x-A x\right\| \rightarrow 0 .
\end{aligned}
$$

For this error bound to be practical, estimates of $\left\|A_{n}^{-1}\right\|$ and $\left\|A_{n} x-A x\right\|$ are needed. Another limitation of (7.5) is the need to assume $R(A)=Y$. We have no Fredholm alternative in this generality.

8. Regular operator approximation. Let $A, A_{n} \in L(X, Y)$. Basic properties, the first in two equivalent forms, are

$\left\{A_{n}\right\}$ asymptotically regular:

$\left\{x_{n}\right\}$ bounded, $\left\{A_{n} x_{n}\right\}$ d-compact $\Rightarrow\left\{x_{n}\right\}$ d-compact,

$\left\{x_{n}\right\}$ bounded, $A_{n} x_{n} \rightarrow y \Rightarrow\left\{x_{n}\right\}^{*} \neq \varnothing$,

regular convergence $A_{n} \stackrel{\mathrm{r}}{\rightarrow} A$ :

$A_{n} \rightarrow A,\left\{A_{n}\right\}$ asymptotically regular.

Examples of regular convergence will be given later. Straightforward reasoning yields

$$
A_{n} \stackrel{\mathrm{r}}{\rightarrow} A \Rightarrow A \text { regular, }
$$

$$
\begin{aligned}
A_{n} & \stackrel{\mathrm{r}}{\rightarrow} A,\left\{x_{n}\right\} \text { bounded, } A_{n} x_{n} \rightarrow y \\
& \Rightarrow y \in R(A), A x=y \quad \forall x \in\left\{x_{n}\right\}^{*} .
\end{aligned}
$$

$$
A_{n} \stackrel{\mathrm{r}}{\rightarrow} A, S \text { closed bounded } \Rightarrow\left\{A_{n} S\right\}^{*}=A S \text {. }
$$

Thus, $A_{n} \stackrel{\mathrm{r}}{\rightarrow} A \Rightarrow\left\{A_{n} U\right\}^{*}=A U$. By (4.1) and (7.3),

$$
\text { when } A_{n} \stackrel{\text { r }}{\rightarrow} A: \exists A^{-1} \Leftrightarrow\left\{A_{n}\right\} \text { stable. }
$$

THeOREM 8.1 (cf. Vainikko [12]).

$$
\begin{aligned}
A_{n} & \stackrel{\mathrm{r}}{\rightarrow} A, \exists A^{-1}, R\left(A_{n}\right)=Y \quad \forall n \text { large } \\
& \Rightarrow A_{n} \stackrel{\stackrel{s}{\rightarrow}}{\rightarrow} A, R(A)=Y, \quad \text { and } A_{n}^{-1} \rightarrow A^{-1} .
\end{aligned}
$$

Proof. By (8.4), $A_{n} \stackrel{\mathrm{s}}{\rightarrow} A$. To show $R(A)=Y$, let $y \in Y$. Let $x_{n}=A_{n}^{-1} y$ $\forall n$ large. Since $\left\{A_{n}\right\}$ is stable, $\left\{x_{n}\right\}$ is bounded. By (8.2), $y \in R(A)$ and $R(A)=Y$. By (7.5), $A_{n}^{-1} \rightarrow A^{-1}$. 
The error bound from (7.5) is theoretical, since regular convergence does not yield an estimate for $\left\|A_{n}^{-1}\right\|$. Another limitation of Theorem 8.1 is the hypothesis that $R\left(A_{n}\right)=Y \forall n$ large.

Next, null spaces and ranges of $A_{n}$ and $A$ are compared with the aid of the set convergence introduced in $\S 2$. For other derivations of some of the results, see Grigorieff [7, 8] and Vainikko [12].

THEOREM 8.2. Let $A_{n} \stackrel{\mathrm{r}}{\rightarrow} A$.

(a) $N\left(A_{n}\right) \cap U \rightarrow N(A) \cap U$.

(b) $\operatorname{dim} N\left(A_{n}\right) \leq \operatorname{dim} N(A) \forall n$ large.

Proof. By (7.1), $\left\{N\left(A_{n}\right) \cap U\right\}^{*} \subset N(A) \cap U$. Since $\left\{A_{n}\right\}$ is asymptotically regular, $\left\{N\left(A_{n}\right) \cap U\right\}$ is d-compact. Theorem 2.1 yields (a). Theorems 3.2 and 6.1 imply (b).

THEOREM 8.3. Let $A_{n} \stackrel{\mathrm{r}}{\rightarrow} A$ and $\exists A^{-1}$.

(a) $\left\{R\left(A_{n}\right)\right\}^{*}=R(A)$.

(b) $\operatorname{dim} F<\infty, R(A) \cap F=\{0\} \Rightarrow R\left(A_{n}\right) \cap F=\{0\} \forall n$ large.

(c) codim $R\left(A_{n}\right) \geq \operatorname{codim} R(A) \forall n$ large if codim $R(A)<\infty$.

(d) $\operatorname{codim} R\left(A_{n}\right) \rightarrow \infty$ if $\operatorname{codim} R(A)=\infty$.

Proof. By (7.1), $R(A) \subset\left\{R\left(A_{n}\right)\right\}^{*}$. From (8.4) and (8.2), $\left\{R\left(A_{n}\right)\right\}^{*}$ $\subset R(A)$. Thus, (a) holds. Lemma 3.1 gives (b).

THEOREM 8.4. Let $A_{n} \stackrel{\mathrm{r}}{\rightarrow} A$.

(a) $R\left(A_{n}\right)$ is closed $\forall n$ large.

(b) $\operatorname{ind}\left(A_{n}\right) \leq \operatorname{ind}(A) \forall n$ large if $\operatorname{ind}(A) \geq-\infty$,

(c) $\operatorname{ind}\left(A_{n}\right) \rightarrow-\infty$ if $\operatorname{ind}(A)=-\infty$.

Proof. By (8.1) and (6.6), $A$ is regular and $\operatorname{dim} N(A)<\infty$. Refer to Lemma 4.1. Now

$$
\begin{aligned}
& A_{n}=A_{n} P+A_{n} Q, \\
& A_{n} P \rightarrow A P=0, \quad \operatorname{dim} R(P)<\infty \Rightarrow\left\|A_{n} P\right\| \rightarrow 0 .
\end{aligned}
$$

It follows easily that $A_{n} Q \stackrel{\mathrm{r}}{\rightarrow} A$. By Theorem 8.2,

$$
\operatorname{dim} N\left(A_{n} Q\right) \leq \operatorname{dim} N(A) \quad \forall n \text { large. }
$$

The restrictions of $A_{n}$ and $A$ to $F$ satisfy

$$
A_{n F} \stackrel{\mathrm{r}}{\rightarrow} A_{F}, \quad \exists A_{F}^{-1} .
$$

By (8.4), (7.2) and $R\left(A_{n F}\right)=R\left(A_{n} Q\right)$, $R\left(A_{n} Q\right)$ is closed $\forall n$ large. 
Now Theorem 8.3, $R\left(A_{n F}\right)=R\left(A_{n} Q\right)$ and $R\left(A_{F}\right)=R(A)$ imply $\operatorname{codim} R\left(A_{n} Q\right) \geq \operatorname{codim} R(A) \forall n$ large if $\operatorname{codim} R(A)<\infty$, $\operatorname{codim} R\left(A_{n} Q\right) \rightarrow \infty \quad$ if $\operatorname{codim} R(A)=\infty$.

So Theorem 8.4 holds for $A_{n} Q \stackrel{\mathrm{r}}{\rightarrow} A$. Lemma 4.2 with $A_{n}=A_{n} P+A_{n} Q$ implies $R\left(A_{n}\right)$ is closed and $\operatorname{ind}\left(A_{n}\right)=\operatorname{ind}\left(A_{n} Q\right)$. The theorem follows. By Theorems 6.1, 8.2, and 8.4:

THEOREM 8.5. $A_{n} \stackrel{\mathrm{r}}{\rightarrow} A \Rightarrow A_{n}$ regular $\forall n$ large.

Regular convergence applies to finite difference approximations for differential equations. See [3], [12]. It also applies to numerical integration approximations of integral equations. However, in the latter situation, sharper results can be obtained from special cases of regular convergence involving compact operators. This is the next topic.

9. Compact operator approximation. Let $K, K_{n} \in L(X)$ for $n \in N$. Key definitions, each expressed in two equivalent forms, are

$\left\{K_{n}\right\}$ collectively compact:

$S$ bounded $\Rightarrow \overline{\cup K_{n} S}$ compact, $\left\{x_{n}\right\}$ bounded $\Rightarrow\left\{K_{m_{n}} x_{n}\right\}$ d-compact $\forall\left\{m_{n}\right\}$,

$\left\{K_{n}\right\}$ asymptotically compact:

$S$ bounded $\Rightarrow\left\{K_{n} S\right\}$ d-compact,

$\left\{x_{n}\right\}$ bounded $\Rightarrow\left\{K_{n} x_{n}\right\}$ d-compact.

It suffices if $S$ is the unit ball in these definitions. Define

collectively compact convergence $K_{n} \stackrel{\mathrm{cc}}{\rightarrow} K$ :

$K_{n} \rightarrow K,\left\{K_{n}\right\}$ collectively compact,

asymptotically compact convergence $K_{n} \stackrel{\text { ac }}{\rightarrow} K$ :

$K_{n} \rightarrow K,\left\{K_{n}\right\}$ asymptotically compact.

By (2.9) and (2.10),

(9.1) $\left\{K_{n}\right\}$ collectively compact

$\Leftrightarrow\left\{K_{n}\right\}$ asymptotically compact, each $K_{n}$ compact, $K_{n} \stackrel{\text { cc }}{\rightarrow} K \Leftrightarrow K_{n} \stackrel{\text { ac }}{\rightarrow} K, \quad$ each $K_{n}$ compact 


$$
K_{n} \stackrel{\mathrm{cc}}{\rightarrow} K \Rightarrow K_{n} \stackrel{\text { ac }}{\rightarrow} K \Rightarrow K \text { compact. }
$$

The difference between $K_{n} \stackrel{\text { cc }}{\rightarrow} K$ and $K_{n} \stackrel{\text { ac }}{\rightarrow} K$ is illustrated by

$$
\left\|L_{n}\right\| \rightarrow 0 \Rightarrow L_{n} \stackrel{\mathrm{ac}}{\rightarrow} 0
$$

$$
K_{n} \stackrel{\mathrm{cc}}{\rightarrow} K, \quad\left\|L_{n}\right\| \rightarrow 0 \Rightarrow K_{n}+L_{n} \stackrel{\mathrm{ac}}{\rightarrow} K,
$$

but $L_{n} \stackrel{\text { cc }}{\rightarrow} 0$ and $K_{n}+L_{n} \stackrel{\text { cc }}{\rightarrow} K$ only when every $L_{n}$ is compact. They are not compact if $L_{n}=c_{n} I, c_{n} \downarrow 0$, and $\operatorname{dim} X=\infty$.

Consider equations

$$
(I-K) x=y, \quad\left(I-K_{n}\right) x_{n}=y .
$$

Examples with $K_{n} \stackrel{\text { cc }}{\rightarrow} K$ are integral equations and numerical integration approximations. See [1], [5]. An example with $K_{n} \stackrel{\text { ac }}{\rightarrow} K$ is a weakly singular integral equation and numerical approximations based on the singularity subtraction technique of Kantorovich and Krylov. The situation in (9.5) arises. See [2].

By an easy argument,

$$
K_{n} \stackrel{\mathrm{cc}}{\rightarrow} K \Rightarrow K_{n} \stackrel{\mathrm{ac}}{\rightarrow} K \Rightarrow I-K_{n} \stackrel{\mathrm{r}}{\rightarrow} I-K .
$$

So Theorem 8.1 applies to solutions of $(I-K) x=y$ and $\left(I-K_{n}\right) x_{n}=y$. However, in the present situation, sharper results are available.

THEOREM 9.1. Let $K_{n} \stackrel{\mathrm{cc}}{\rightarrow} K$ or $K_{n} \stackrel{\mathrm{ac}}{\rightarrow} K$.

(a) (Fredholm alternative) $\forall n$ large,

$$
\begin{aligned}
& R\left(I-K_{n}\right)=X \Leftrightarrow \exists\left(I-K_{n}\right)^{-1} \\
& \quad \Rightarrow\left(I-K_{n}\right)^{-1} \in L(X), \operatorname{dim} N\left(I-K_{n}\right)=\operatorname{codim} R\left(I-K_{n}\right)<\infty . \\
& \text { (b) }\left\|\left(K_{n}-K\right) K\right\| \rightarrow 0,\left\|\left(K_{n}-K\right) K_{n}\right\| \rightarrow 0 \text { as } n \rightarrow \infty . \\
& \text { (c) } \exists(I-K)^{-1} \Leftrightarrow \exists\left(I-K_{n}\right)^{-1} \text { uniformly bounded } \forall n \text { large, }
\end{aligned}
$$
in which case $\left(I-K_{n}\right)^{-1} \rightarrow(I-K)^{-1}$ on $X$ and there are practical error bounds.

Theorem 9.1 is presented under the collectively compact hypothesis in [1]. While many of the proofs from the classical compact operator theory [11] apply under the weaker hypothesis, a different approach will be taken in the sequel which will handle both the collectively and asymptotically compact cases with equal efficiency. The regular convergence in (9.7) will prove useful in this regard. 


\section{REFERENCES}

[1] P. M. Anselone, Collectively Compact Operator Approximation Theory, Prentice-Hall, 1971.

[2] _ Singularity subtraction in the numerical solution of integral equations, J. Austral. Math. Soc., (Series B) 22 (1981), 408-418.

[3] P. M. Anselone and R. Ansorge, Compactness principles in nonlinear operator approximation theory, Numer. Funct. Anal. and Optim., 1 (6), (1979), 598-618.

[4] , A unified framework for the discretization of nonlinear operator equations, Numer. Funct. Anal. and Optim., 4 (1), (1981), 61-99.

[5] K. E. Atkinson, A survey of numerical methods for the solution of Fredholm integral equations of the second kind, SIAM Publications, 1976.

[6] F. Chatelin, The spectral approximation of linear operators with applications to the computation of eigenelements of differential and integral operators, SIAM Review, 23 (1981), 495-522.

[7] R. D. Grigorieff, Zur Theorie Linearer approximations regulärer Operatoren I, Math. Nachr., 55 (1973), 233-249.

[8] _ Zur Theorie Linearer approximations regulärer Operatoren II, Math. Nachr., 55 (1973), 251-263.

[9] T. Kato, Perturbation Theory for Linear Operators, 2nd Ed., Springer-Verlag, 1976.

[10] F. Stummel, Discrete convergence of mappings, Proc. Conf. Numer. Anal., Dublin, 1972, pp. 285-310, Academic Press, 1973.

[11] A. E. Taylor and D. C. Lay, Introduction to Functional Analysis, Wiley, 1980.

[12] G. Vainikko, Funktionalanalysis der Diskretisierungsmethoden, Teubner, Leipzig, 1976.

[13] R. Wolf, Über lineare approximationsreguläre Operatoren, Math. Nachr., 59 (1974), 325-341.

[14] B. Yood, Properties of linear transformations preserved under addition of a completely continuous transformation, Duke Math. J., 18 (1951), 599-612.

Received January 31, 1984.

OREgon State UNIVERSity

CORVALlis, OR 97331

AND

IOWA STATE UNIVERSITY

AMES, IA 50011 


\section{PACIFIC JOURNAL OF MATHEMATICS EDITORS}

\author{
V. S. VARADARAJAN (Managing Editor) \\ University of California \\ Los Angeles, CA 90024 \\ Charles R. DePrima \\ California Institute of Technology \\ Pasadena, CA 91125 \\ R. FINN \\ Stanford University \\ Stanford, CA 94305
}

\author{
HeRmanN FlaschKa \\ University of Arizona \\ Tucson, AZ 857.21
}

RAMESH A. GANGOLli

University of Washington

Seattle, WA 98195

ROBION KIRBY

University of California

Berkeley, CA 94720
C. C. MOORE

University of California

Berkeley, CA 94720

H. SAMELSON

Stanford University

Stanford, CA 94305

HAROLD STARK

University of California, San Diego

La Jolla, CA 92093

\section{ASSOCIATE EDITORS}
R. ARENS
E. F. BECKENBACH
B. H. NeumanN
F. WOLF
K. YoSHIDA
(1906-1982)

\section{SUPPORTING INSTITUTIONS}

\begin{abstract}
UNIVERSITY OF ARIZONA
UNIVERSITY OF BRITISH COLUMBIA

CALIFORNIA INSTITUTE OF TECHNOLOGY

UNIVERSITY OF CALIFORNIA

MONTANA STATE UNIVERSITY

UNIVERSITY OF NEVADA, RENO

NEW MEXICO STATE UNIVERSITY

OREGON STATE UNIVERSITY
\end{abstract}

\author{
UNIVERSITY OF OREGON \\ UNIVERSITY OF SOUTHERN CALIFORNIA \\ STANFORD UNIVERSITY \\ UNIVERSITY OF HAWAII \\ UNIVERSITY OF TOKYO \\ UNIVERSITY OF UTAH \\ WASHINGTON STATE UNIVERSITY \\ UNIVERSITY OF WASHINGTON
}

The Supporting Institutions listed above contribute to the cost of publication of this Journal, but they are not owners or publishers and have no responsibility for its content or policies.

Mathematical papers intended for publication in the Pacific Journal of Mathematics should be in typed form or offset-reproduced (not dittoed), double spaced with large margins. Please do not use built up fractions in the text of the manuscript. However, you may use them in the displayed equations. Underline Greek letters in red, German in green, and script in blue. The first paragraph must be capable of being used separately as a synopsis of the entire paper. In particular it should contain no bibliographic references. Please propose a heading for the odd numbered pages of less than 35 characters. Manuscripts, in triplicate, may be sent to any one of the editors. Please classify according to the scheme of Math. Reviews, Index to Vol. 39. Supply name and address of author to whom proofs should be sent. All other communications should be addressed to the managing editor, or Elaine Barth, University of California, Los Angeles, California 90024.

There are page-charges associated with articles appearing in the Pacific Journal of Mathematics. These charges are expected to be paid by the author's University, Government Agency or Company. If the author or authors do not have access to such Institutional support these charges are waived. Single authors will receive 50 free reprints; joint authors will receive a total of 100 free reprints. Additional copies may be obtained at cost in multiples of 50 .

The Pacific Journal of Mathematics is issued monthly as of January 1966. Regular subscription rate: $\$ 190.00$ a year (5 Vols., 10 issues). Special rate: $\$ 66.00$ a year to individual members of supporting institutions.

Subscriptions, orders for numbers issued in the last three calendar years, and changes of address should be sent to Pacific Journal of Mathematics, P.O. Box 969, Carmel Valley, CA 93924, U.S.A. Old back numbers obtainable from Kraus Periodicals Co., Route 100, Millwood, NY 10546.

The Pacific Journal of Mathematics at P.O. Box 969, Carmel Valley, CA 93924 (ISSN 0030-8730) publishes 5 volumes per year. Application to mail at Second-class postage rates is pending at Carmel Valley, California, and additional mailing offices. Postmaster: Send address changes to Pacific Journal of Mathematics, P.O. Box 969, Carmel Valley, CA 93924.

PUBLISHED BY PACIFIC JOURNAL OF MATHEMATICS, A NON-PROFIT CORPORATION

Copyright $\odot 1985$ by Pacific Journal of Mathematics 


\section{Pacific Journal of Mathematics}

Vol. 120, No. $2 \quad$ October, 1985

Philip Marshall Anselone and Mike Treuden, Regular operator

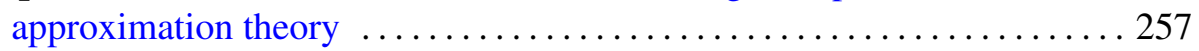

Giuseppe Baccella, Semiprime $\aleph-Q F 3$ rings $\ldots \ldots \ldots \ldots \ldots \ldots \ldots \ldots . \ldots \ldots$

Earl Robert Berkson and Thomas Alastair Gillespie, The generalized M.

Riesz theorem and transference $\ldots \ldots \ldots \ldots \ldots \ldots \ldots \ldots . \ldots 279$

Joachim Boidol, A Galois-correspondence for general locally compact

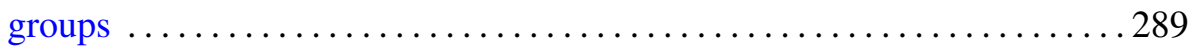

Joseph Eugene D'Atri, Josef Dorfmeister and Yan Da Zhao, The isotropy

representation for homogeneous Siegel domains ............... 295

C. Debiève, On Banach spaces having a Radon-Nikodým dual

Michael Aaron Freedman, Existence of strong solutions to singular

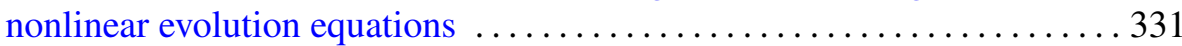

Francisco Jose Freniche, Grothendieck locally convex spaces of continuous

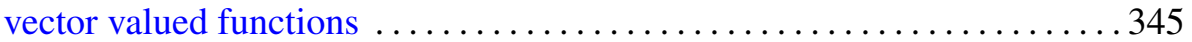

Hans-Peter Künzi and Peter Fletcher, Extension properties induced by complete quasi-uniformities . ............................ 357

Takaŝi Kusano, Charles Andrew Swanson and Hiroyuki Usami, Pairs of

positive solutions of quasilinear elliptic equations in exterior domains . . 385

Angel Rafael Larotonda and Ignacio Zalduendo, Spectral sets as Banach

manifolds

J. Martínez-Maurica and C. Pérez García, A new approach to the

Kreı̆n-Milman theorem

Christian Pommerenke, On the boundary continuity of conformal maps . . . 423

M. V. Subba Rao, Some Rogers-Ramanujan type partition theorems

Stephen Edwin Wilson, Bicontactual regular maps .........

Jaap C. S. P. van der Woude, Characterizations of (H)PI extensions

Kichoon Yang, Deformation of submanifolds of real projective space

Subhashis Nag, Errata: "On the holomorphy of maps from a complex to a

real manifold" 